\title{
Aproximación a la estética indígena
}

Approach to indigenous aesthetics

Aproximação à estética indígena

Luis Galindez*

\section{Resumen}

Para la compresión del presente artículo es importante exponer algunas reflexiones históricas sobre la estética, comenzando por una breve síntesis de la filosofía estética occidental. Luego de considerar los criterios eurocéntricos de dominación estética, se aborda las ideas sobre pensamiento latinoamericano y la estética de los pueblos indígenas en Venezuela. Finalmente, importantes valoraciones artísticas latinoamericanas, así como interesantes aportes del arte contemporáneo en Venezuela, caso Mito de Amalivaca. La estética indígena como objeto del conocimiento sensible, dentro de las prácticas sociales (míticos-simbólicas), estimula el interés por la re-existencia y visibilización de nuestros pueblos originarios.

Palabras clave: Arte. Estética indígena. Valoración.

\section{La Filosofía Estética de 0ccidente}

La estética occidental fue considerada inicialmente como una rama filosófica que tenía su objeto de estudio en la esencia y la percepción de la belleza. La consideraron como ciencia involucrada con los procesos reflexivos sobre los problemas del arte, encargada de interpretar filosóficamente los valores contenidos en las obras de arte como manifestaciones culturales. Este discurso contribuyó directa o indirectamente a devaluar y colonizar las expresiones de sentir de las sociedades no occidentales desde el siglo XVIII hasta hoy.

El discurso estético-filosófico europeo, construyó su pasado en la antigua Grecia, y Roma, a través de los enunciados presocráticos. Etimológicamente, su denominación tiene su origen en la acepción de las voces griegas aisthetis, que significan "sensación". Tales como criterios y categorías para sentir,

\footnotetext{
Doctor en Cultura y Arte para América Latina y El Caribe, Universidad Pedagógica Experimental Libertador, Instituto Pedagógico de Caracas, Venezuela. Magister en Artes Plásticas (UPEL-IPC). Profesor en Artes Plásticas y Apreciación artística. Artista plástico. E-mail: lugalopez@hotmail.com
}

Recebido em 13.08.2018 - Aprovado em 21.09.2018 http://dx.doi.org/10.5335/hdtv.19n.1.8909 
valorar y teorizar se establecieron en mundo Moderno occidental.

Filósofos como Platón y Aristóteles, apuntaron su interés por la belleza, lo poético, la tragedia y la imitación. La concepción griega divide la belleza en dos grandes categorías: la belleza natural y la belleza artística. La primera representa el mayor grado de perfección posible; mientras que la segunda consiste en imitación de la primera: la mimesis.

En Occidente, la historia de la reflexión filosófica acerca de las artes se inició con Platón. Su importante contribución fue precedida por su exploración sobre el juicio estético. Platón consideraba que la realidad se compone de formas que están más allá de los límites de la sensación de humana y que constituyen modelos de todas las cosas que forman parte de la experiencia humana. Los objetos que los seres humanos experimentan son ejemplos o imitaciones de esas formas. Lo que se procura, a través de la reflexión filosófica, es la comprensión de las formas y no de las copias. El artista copia el objeto experimentado, o lo utiliza como modelo para su obra. Para el filósofo, en cambio, la belleza reside en la idea y no en las cosas sensibles. La belleza de las cosas sensibles es derivada con participación de las formas inteligibles.

Aristóteles enfocó la belleza desde otra perspectiva. La belleza no es un medio para conseguir un fin, sino un fin en sí; es decir, una cualidad inmediata. Distingue entre fin y medio, identificando este último con lo útil. Útiles son todos los bienes cotidianos que no llegan a convertirse en medio para algo. Lo bello, en cambio, no es arbitrario, contingente, ni irracional. Esto ha servido de base para que su estética sea calificada de racionalista. La belleza está contenida en la simetría, a la que considera el símbolo de lo perfecto, ligado al concepto clásico de belleza: armonía, orden y proporción.

Hacia 1750, Baumgarten, (1714-1762) filósofo alemán contemporáneo con Kant, publica su obra titulada Estética, en la que definió "la estética como ciencia del conocimiento sensible, del conocimiento de un objeto" (BAUMGARTEN, 1750-1758 apud COLOMBRES, 2005, p. 183). El filósofo subordinó el conocimiento filosófico de la belleza a la sensibilidad y recuperó el antiguo término utilizado entre los griegos (aisthesis = percepción sensible; aisthanomai $=$ percibir por los sentidos). El estudio de Baumgarten se centró en la teoría de la percepción sensible, el sentir de la naturaleza y éste reafirmaba que la esencia de lo bello no podía darse sin el descubrimiento del placer sensible estético. Lo bello y lo estético no son ajenos a lo sensible. Lo que comprende lo artístico es dado por medio de la sensibilidad. El filósofo fundó la estética como disciplina independiente, basada esencialmente en las conjunciones de arte y belleza.

Entre los elementos que contribuyen a la construcción estética de Baumgartem, está el descubrir la facultad del objeto estético, la belleza como objeto del conocimiento estético y la concepción de la verdad estética.

A través del conocimiento sensible, Baumgartem plantea una estética como ciencia del conocimiento sensible, que se ocupa de la belleza. "El fin de la estética es la perfección del conocimiento sensible en cuanto tal y esto es la belleza". Baumgartem ubica la estética en el ámbito del conocimiento: “el 
arte de pensar hermosamente". El filósofo alemán trata de ver cómo usar las facultades inferiores para conseguir la máxima perfección. Es una ciencia que se ocupa de una actividad concreta del pensamiento humano (el conocimiento inferior) y la contribución de Baumgartem consistió en mostrar que la intuición sensible tiene sus leyes internas, su propia lógica.

El filósofo alemán Kant (1729-1804), desde los juicios del gusto estético, propuso en su obra Crítica del juicio (1790) que los objetos pueden ser juzgados bellos cuando satisfacen un de seo desinteresado que no implique interés o necesidad personal. En la estética kantiana no se examina el arte en sí, sino la facultad de juzgar. El objeto bello no tiene propósito específico y los juicios de belleza no son expresiones de las simples preferencias personales.

Para Kant, la estética toma el sentido de ciencia de la sensibilidad. El filósofo alemán se interesa en el arte por su vinculación con la belleza, no por el arte mismo. La belleza, de acuerdo con Kant, no es una cualidad propia de las cosas bellas producidas por los artistas, sino un sentimiento de placer del sujeto que juzga las cosas como bellas, sean ellas obras de arte o de la naturaleza. Su estética es una estética subjetiva, cuya primera premisa es el juicio del gusto, aplicado indistintamente a objetos del arte o de la naturaleza.

Hegel (1770-1868), en su tesis, estableció que la estética era una ciencia que se ocupa no de las sensaciones sino de la filosofía del arte. Para Hegel, el arte supone la plataforma máxima de la elevación espiritual.
Durante los siglos XVIII y XIX, la estética permaneció dominada por el concepto del arte como imitación de la naturaleza. Los pintores neoclásicos, como Jean Auguste Dominique Ingres, románticos, como Eugène Delacroix, o realistas, como Gustave Courbet, representaban sus temas extremando el cuidado en el detalle natural. En la estética tradicional, se asumía también con frecuencia que las obras de arte eran tan útiles como bellas. Los cuadros podían conmemorar eventos históricos o estimular la moral.

En el siglo XIX, no obstante, conceptos vanguardistas aplicados sobre la estética empezaron a cuestionar los enfoques tradicionales. El cambio fue muy evidente en la pintura. Los impresionistas franceses, como Claude Monet, fueron objeto de críticas severas, por los pintores academicistas, por representar una realidad sorprendente ante los ojos de estos, capaces de observar más de lo que realmente veían, como eran las superficies de muchos colores y formas oscilantes causadas por el juego distorsionante de luces y sombras.

A finales del siglo XIX, los postimpresionistas, como Paúl Cézanne, Paúl Gauguin y Vincent Van Gogh, estuvieron más interesados en la estructura pictórica y en expresar su propia psique que en representar objetos del mundo de la naturaleza. A principios del siglo XX, este interés estructural fue desarrollado por los pintores cubistas como Pablo Ruiz Picasso, mientras que la inquietud expresionista se reflejaba en la obra de Henri Matisse y otros fauvistas, así como en expresionistas alemanes de la categoría de Ernst Ludwig Kirchner. 
En estrecha relación con estos enfoques, hasta cierto punto no figurativo del mundo plástico, cobró relevancia el principio del "arte por el arte", derivado de las tesis de Kant según las cuales el arte tenía su propia razón de ser.

\section{Ideas sobre la estética indígena: pensamiento latinoamericano}

Las ideas estéticas del mundo occidental dominaron el pensamiento latinoamericano a través de la incursión del colonialismo y los dominios de los grandes aparatos económicos que permitieron la aplicación de los conceptos estéticos de belleza y bellas artes como orden y juicio universal. En muchos casos, esas ideas estéticas fueron utilizadas por historiadores del arte, críticos de artes, etnólogos y filósofos latinoamericanos para valorar las producciones artísticas de nuestra cultura indígena. Refiere Colombres, que

Toda dominación cultural y estética, cualquiera sea el contexto en que opere, implica de hecho una negación de la diversidad puede generar propuestas tanto o más válidas que las del sector dominante. O sea, la dominación consiste en negar el arte de los otros la tal condición de tal, o, en el mejor de los casos reconocer algún valor pero declarado inferior (2005, p. 290).

En su afán de dominación, la estética colonialista siempre consideró los objetos artísticos de los pueblos indígenas como obras del espíritu, separadas de su entorno social, no así la antropóloga Lelia Delgado, considera que:
Los fenómenos estéticos de las sociedades aborígenes, además de ser fenómenos de la sensibilidad, se vieron profundamente imbricados con todos los aspectos de la práctica social, sea ésta mágico-religiosa, política, etc.; esto los diferencia del arte, un sistema de producir objetos que se fundamenta en la autonomía. Este sistema es una forma peculiar, pero no excluyente, de estructurar la actividad estética $(1989$, p. 22).

Delgado (1989) reflexiona sobre la teórica estética indígena. Considera que ésta obedece a una intención de reconocer y validar las apreciaciones estéticas de la cultura indígena para refirmar una posición más endógena y no las pretensiones de crear o profundizar sobre una teoría de la estética prehispánica en sí. En este sentido, desde esta teoría estética, se debe tratar de reconocer el contexto del pensamiento estético, construido por cualquier pueblo indígena, desde su cultura.

En su libro, Seis ensayos sobre Estética Prehispánica en Venezuela (1989), prefiere analizar los componentes estéticos de la práctica social de las comunidades aborígenes, al margen de las nociones colonialistas del arte como se lo entiende en occidente. Para la investigadora, se trata de fenómenos distintos aunque posean elementos en común.

No obstante, el antropólogo Velásquez, en su estudio Estética aborigen (2003), se apropia de aspectos de la culturas originarias, en su planteamiento, manifestaciones o representaciones de la cultura indígena, la estética aborigen surgen desde una comunicación hierofánica (un objeto determinado que ostenta un valor religioso), en este particular, sí pertenece a la concepción netamente aborigen. 
De igual manera, Calzadilla (2010), para discernir sobre el arte prehispánico y explicar la producción artística-estética del humano primigenio en su proceder y producción inicial. La autora, circunscribir la estética indígena, al conocimiento sensible y ubica la producción artística en el ámbito de las representaciones sensibles.

Por otro lado, Colombres (2005) no considera la experiencia estética como categoría filosófica que se encuentre en todas los pueblos. La experiencia estética se desarrolló junto con la conciencia y habilidades manuales del hombre que comenzó hace 500 mil años. El hombre transformó su visión del trabajo y elevó su conciencia entre medios y fines y las establecidas entre forma y función. El hombre buscó qué formas dar a los objetos para que cumplieran mejor la función que se asignara. A la necesidad de elaborar objetos acompañados de sus cualidades, materia, forma, y tamaño para que cumplieran sus funciones, agregó la impronta plástica, imprimiendo, pintando con colores o realizando aplicaciones en relieves e incisiones. Esto condujo a la existencia de una nueva función, ligada a lo mágico y al carácter simbólico. Según Colombres, la experiencia estética surge del recubrimiento de bellas formas y colores para impresionar los sentidos y aumentar la intensidad del ritual; en la conciencia de que ello se traducirá en una mayor eficacia de éste en los que hace al cumplimiento de su fin mágico.

Mendiola Galván (2002) explica que el estudio del arte rupestre implica per se un problema de conocimiento y que, en estricto orden epistemológico, debe observarse que este tipo de arte se explica en sí mismo como conocimiento por su origen, carácter, estructura, método y explicaciones que lo validan como arte.

El antropólogo refiere que la estética, aunque paradójico parezca, posee en sus manos parte de los elementos teóricos de explicación precisamente en relación con los componentes estéticos de la práctica social, de la sensibilidad en la percepción y transformación estética de la realidad, contenidos todos en arte rupestre.

Para el filósofo Sánchez Vázquez, citado por Mendiola Galván:

La relación estética, embrionaria y difusa en sus comienzos, es una de las formas más antiguas de relación del hombre con el mundo. Es anterior no sólo al derecho, la política, la filosofía y la ciencia, sino incluso a la magia, al mito y la religión aunque no anterior -sino vinculada estrechamente en sus orígenes a la producción material de objetos útiles (VÁZQUEZ, 1992 apud MENDIOLA GALVÁN, 2002, p. 3).

La experiencia estética que experimentó el hombre que representó (pintón y grabó) en las superficies rocosa, deviene de la relación con su entorno social. En ésta, él hace, crea sus objetos y es impulsado por esa realidad que emotivamente lo estimula a dar respuestas, causadas o provocada por la sed, hambre muerte o miedo a la misma, quizás por la ingestión de psicotrópicos, que pudieran combinarse con los fenómenos naturales observados: la oscuridad, el sol, la luna, las estrellas, los eclipses, el agua, la lluvia, el frío, el viento, los terremotos, los animales o también las producidas por la relación con los seres humanos, la guerra, el sexo, la reproducción biológica y fertilidad, la tierra, las plantas, las montañas, la noche 
o el día, emociones producto de todos estos factores y hechos de la naturaleza generaron una experiencia profunda en su actitud estética que por lo general está ligada a su realidad religiosa, a su actos rituales.

Actitudes que en su conjunto sensible, consciente o inconscientemente, según Mendiola Galván (2002), se derivan de la experiencia estética al haberse transformado (estéticamente) la realidad del pasado y del presente y que va de la graficación a la observación del producto graficado. En su observación al material estético-sensible, el indígena apreció la capacidad de abstracción que implica la grafía, sea el diseño naturalista, realista, abstracto o geométrico como un conjunto sensible, que en su modificación grafica les produce efectos emotivos, definidos como bonitos, feos, admirables, importantes, útiles o inútiles, calificativos que sensiblemente nos genera su observación confirmando la abstracción que envuelve la grafía.

Sobre el estudio de la grafía rupestre han surgidos explicaciones lógicas desarrolladas desde el contexto arqueológico, etnohistórico, semiótico y lingüístico, pero a decir de Mendiola Galván (2002), la grafía permanece inmutable ante las mil y una interpretaciones que se le adjudican, provocando por otra parte, que este material cultural se ignore como productor de efectos emotivos y agente de transformación estética de la realidad.

En la aproximación a visiones de estética de las culturas indígenas, es observable que sus expresiones artísticas estén cargadas de referencias gráficas, simbólicas, mágicas, míticas, y religiosas que son inherentes a la experiencia humana, donde el arte, como fenómeno estético, expresa de manera visible y dinámica los contenidos de las prácticas sociales en el contexto de cada cultura, acompañadas de las apreciaciones formales plástica, cromática, temática y simbólica de los fenómenos estéticos pasados.

\section{Estética de los pueblos indígenas en Venezuela}

Las primeras interpretaciones y estudios sobre las expresiones estético-artísticas de los pueblos indígenas califican las expresiones artísticas como arte prehispánico (una clara apreciación colonialista). Algunas expresiones fueron catalogadas e insertas en diversos periodos o etapas en la que se incluyeron las especulaciones teóricas de cronistas europeos de los siglos XV y XVI, así como la de los viajeros del siglo XIX. Según Delgado (1989), este último siglo se caracterizó por la multiplicidad de interpretaciones un tanto fantasiosas y por la falta de sistemas de trabajo. A finales de siglo XIX y comienzo del XX surgió la etapa descriptiva que estuvo influenciada por las ideas positivistas. La misma estuvo marcada por el estudio del hombre y la cultura que aportaba la antropología eurocéntrica.

En otros estudios sobre el arte prehispánico (concepción eurocéntrica) en Venezuela, durante los años 50 y 60, las investigaciones se ocuparon de las explicaciones de los procesos socio- históricos de las sociedades antiguas. En esta dirección, se aprecia los estudios de De la Plaza quien se interesó por las huellas del arte a partir del hombre primitivo, elaborando un estudio compara- 
tivo del arte antiguo. Éste dedicó sus estudios del arte a otros países y pueblos indígenas. Para Delgado (1989), este investigador omite las prácticas estéticas de las culturas indígenas de venezolanas.

En el estudio sobre arte prehispánico en Venezuela, los antropólogos Arroyo y Cruxent (1973) elaboraron una serie de características generales en los periodos mesoindio, neoindio, clásico, y postclásico de las diferentes regiones del país, la mayor parte de los estudios versaron sobre la cerámica indígena del país, Tales características obedecen a cualidades significativas y plásticas de los objetos hallados, más que el sentir y pensar de la cultura material del país. Por otro lado, Boulton (1978) realizó algunas apreciaciones desde una visión coleccionista del arte prehispánico, tomando como eje de trabajo la cerámica y los objetos líticos.

Por lo general, las indagaciones del arte indígena están seguidas de abundantes descripciones, asociaciones, análisis, intentos de asignaciones culturales y cronológicas, así como también interpretaciones por la vía científica del material cultural. En su conjunto, se trata de problemáticas comunes inherentes a lo indígena y que en gran medida han sido de difícil solución, aún con los adelantos tecnológicos de registro y refinados métodos de análisis y de una mayor integración de diversas posturas teóricas, muchas de ellas con argumentos muy importantes en sus explicaciones, pero que en lo general, no han podido trascender la conjetura o el ámbito de las posibilidades en relación con los reales y verdaderos significados de la gráfica indígena, cualesquiera que éstos sean. Por otro lado, la mayor parte de los estudios sobre el arte "prehispánico" se elaboraron siguiendo concepciones teóricas eurocéntricas; el encuentro con las expresiones artísticas permanece como objeto poco sensible a las apreciaciones internas.

Siguiendo a Delgado, "las apreciaciones de arte prehispánico" (1989, p. 28) se hicieron a partir del ideal estético occidental único reconocido y valido, esto permitió a los pioneros juzgar las artes de nuestros pueblos primitivos como objetos previos, tanto en el tiempo como en el grado de evolución.

La diversidad de estos pueblos indígenas asentados en nuestro territorio definió el arte prehispánico de Venezuela. Como se ha señalado anteriormente, este arte se caracteriza por tener una función principalmente mítica y es realizado por los habitantes originarios, dotados de una sensibilidad artista que valora sus contenido funcional, práctico, mágico-religioso, ideológico, simbólico, ceremonial o festivo de su Arte, expresado a través de la arquitectura, la cerámica, el textil, la pintura corporal y los grandes mitos que dan origen a su cultura. Para el creador indígena, todo está vinculado a su propio espacio cultural. Cultura que está condicionada a su medio ambiente, sus necesidades económicas, creencias, ritos y formas de vida. El indígena vivió y vive en constante equilibrio con la naturaleza; tomó de ella lo que necesitó y aún tiene esta práctica como respeto a ese mundo que es el hacedor de sus días.

A través de estas manifestaciones artísticas, el creador indígena plasma toda la magia y da explicación a su mundo. Han sido las mejores vías que han utilizado los 
arqueólogos para medir, comparar y contrastar las culturas indígena, que es considerada expresión muy significativa y original.

La cerámica prehispánica presenta caracterizas muy definidas, ya por su función $\mathrm{o}$ aspecto religioso, tales como recipientes se identifican como vasijas, bol, vasos y botellas. Por su forma, se distinguen en global, semi-esférica, con asas o sin asas, con uno o dos vertederos, con tres o cuatro patas (tripoides, retrópodos), con diversas bases, bordes, cuellos y tamaños y las figuras o piezas antropomorfas y zoomorfas. Al inicio, el hombre indígena creaba estos objetos sin adornos, lisos, luego aprende a decorarlos con incisiones sobre la pasta aún blanda. La que ofrece mayor cantidad, valor y calidad es la cerámica. Se dice que el material más estudiado por los arqueólogos venezolanos y extranjeros es la cerámica.

Por su variedad de ornamentación, se denominan en Modelada, Aplicada, en relieve, Acanalada, Incisa, Excisa, Punteada, y Pintada. En cuanto a su Motivos decorativos, pueden ser de figuras humanas (antropomorfas), de figuras de animales (zoomorfas). Otras decoraciones son: Figuras geométricas, Bandas, Diversas líneas, la superficie puede ser lisa o rugosa sin pulir. En cuanto al color, suele utilizarse el propio de la arcilla o del barro, o también el determinado por el engobe (Engobe es una capa superficial de mezclilla de arcilla fina, disuelta con el agua aplicada a la superficie). Este le da un colorido blanco, beige o marrón claro.

Son características las figuras antropomorfas y zoomorfas: la mayoría de las figuras zoomorfas, se refiere a la fauna regional. Los animales más comunes: jaguares, monos, cachicamos, chigüires, caimanes, serpientes, ranas, murciélagos, diferentes aves y caracoles propios de la región que habitan los pueblos indígenas.

Figura 1 - Venus de Tacarigua

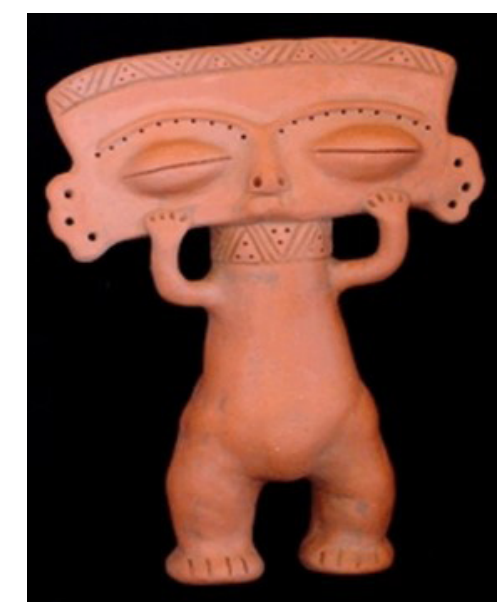

Fuente: <https://escritorasunidas.blogspot.com/2011/06/america-precolombina-venus-de-tacarigua.html>. ${ }^{1}$

En las excavaciones de los diferentes yacimientos en Venezuela, se han encontrado piezas inmunes; y los hallazgos de cerámica policroma que refieren a piezas más antigua en centro y Sudamérica (más de 1.000 años A.P.).

Las manifestaciones pictóricas son llamadas, también, pinturas rupestres. Estas pinturas se han localizado en diversas regiones del mundo, generalmente en las paredes de cuevas y cavernas, alcanzando grandes dimensiones. El arte de la pintura en los indígenas, representa un simbolismo especial relacionado con sus costumbres ancestrales, mitos y religión.

Algunos antropólogos sostienen que los grupos étnicos venezolanos realizaron una gran cantidad de pintura rupestre, sobre 
las paredes de las cuevas, con fines sagrados. Estos hallazgos constituyen una buena muestra de la necesidad de expresión plástica de las etnias venezolanas. Las pinturas rupestres también son llamadas "pictografía", las formas representadas son antropomorfas, zoomorfas y geométricas, de líneas sencillas, de un solo trazo o compuesta de varios trazos paralelos.

Los yacimientos con mayor cantidad y variedad de pinturas rupestres se encuentran en la "La Cueva de la Virgen" en el Edo. Aragua y entre otros, está "La Gruta del Corral Viejo". "La Cueva del Elefante", en el Edo. Bolívar, que recibe ese nombre porque está cerca de una gran piedra (de 60 a 80 metros de altura), la cual tiene forma de elefante. Las pictografías se hallan en una pared, de 40 metros, de largo por 3 metros de ancho, compuestas por figuras antropomorfas (incompletas) y zoomorfas (muy estilizadas), junto a signos abstractos, como círculos concéntricos, impresiones de manos y representaciones de objetos utilitarios como armas y cestas. Es en las cuevas donde se encuentran las pinturas rupestres, se dieron los primeros rituales de iniciación: la entrada y salida a la vida; allí se enseñaron los conocimientos sagrados y profanos que rigieron sobre los primeros hombres. En sus paredes están representados numerosos diseños de cestería, muchos de los diseños parecen ser marcas claniles, al igual que los encontrados en los petroglifos, que visualmente transmiten las leyes exogámicas para garantizar una exitosa descendencia.

Además de realizar las pinturas rupestres, los pueblos indígenas desarrollaron con buen acierto la pintura corporal, aspecto que aún se mantiene vigente en muchas comunidades.

Dentro del gran acontecimiento que implica el haber hallado restos de pintura mural o rupestre, se encuentran los petroglifos y los geoglífos que se toman también como manifestaciones expresivas de las culturas prehispánicas venezolanas.

\section{Los atavíos corporales}

Los atavíos corporales del hombre prehispánico adquieren un significado mágico-religioso dentro de su contexto cultural. Los cronistas, misioneros y expedicionarios escribieron sobre los vistosos collares, penachos y Coronas de Plumas de variados colores, cuyo uso como adorno, observaron en los indígenas, coronas hechas de plumas de gavilán o de guacamaya dispuestas en los bordes de rayos eran propias de los shamanes o capitanes. Delgado (2010) sostiene que en el caso de los objetos plumarios, no se trata de cualquier ave, no es cualquier color que se utilice para hacer una corona plumaria o para enmarcar una maraca chamánica; eso no es un instrumentos musical, sino que es un instrumento médico que cura; no es cualquier pluma, es la pluma del ave sagrada que le corresponde, que ayudó, por ejemplo, a Wanai, ser supremo de los yekuana, en un momento de toda la epopeya que implicó construir el mundo.

En el material arqueológico de las tumbas indígenas, se han encontrado diversos collares entre el material arqueológico de las tumbas indígenas fabricados con perlas, oro, conchas marinas, huesos y piedras semi preciosas, tales como la malaquita, el jaspe o la serpentina. 
Los diferentes grupos indígenas prehispánicos que lograron establecerse en ciertas áreas del territorio venezolano, dejaron clara muestra de su cultura, creencias, actividades y aptitudes artísticas. Los hallazgos de ornamentaciones, como vasijas preparadas con barro, cerámica, etc., dan fe de la calidad de sus trabajos. Las construcciones de viviendas y adornos hechos con metales osamentas, muestran las creencias en lo sagrado y sobrenatural, con un alto contenido simbólico

El mito, la magia y la religión constituyen la base fundamental de la creación que se dan y que están allí formando parte de su cotidianidad; son expresión plástica de las culturas originarias.

\section{Estética y arte indígena:valoración artística latinoamericana}

Durante el siglo XIX, la estética latinoamericana se expresaba desde los modelos eurocéntricos. Frente a ella, se realizaban las producciones simbólicas más interesantes de nuestros grupos étnicos y la de los sectores populares mestizos. Ambas eran consideradas oficios artesanales, las ideas de la una estética eurocéntrica no las asume como arte.

Un antecedente importante, para la compresión del arte comprometido en Latinoamérica fue el desarrollo que toma el realismo socialista en la Unión Soviética a partir de la revolución de 1917, este movimiento artístico nace para enfrentar e interpretar la realidad del momento y constituyó un instrumento educativo para la formación de la conciencia proletarizada. Los sucesos sociales y políticos en la Rusia de 1917 llevan al proletariado al poder y esto hace que la sociedad artística se plantee la necesidad de una nueva estética y, por ende, el camino del arte. Los artistas de la Rusia de 1910 adoptaron el término realismo socialista.

Para la investigadora Beatriz Calzadilla (2004), el realismo socialista exige del artista una representación verídica, históricamente concreta de la realidad, en su desarrollo revolucionario. La autora, igualmente señala que la concepción artística denominada realismo socialista tuvo como objetivo: "la destrucción del capitalismo, reflejar la verdad de la vida y la lucha por la subsistencia, inculcar el trabajo colectivo y servir de instrumento ideológico en la construcción de una sociedad socialista feliz" (2004, p. 55).

A partir de la segunda década del siglo XX surgió en los sectores intelectuales y artísticos de las sociedades latinoamericanas manifestaciones claras de un arte visual más comprometido con las reivindicaciones sociales y culturales, estas manifestaciones artísticas, buscaban su independencia de los asomos metropolitanos, asumiendo temas y elementos de las tradiciones formales, tanto populares como indígenas

Entre 1910-1920 en medio de la revolución y producto del desbordamiento de las academias de bellas artes México se levanta con el realismo social, como uno de los países latinoamericano en valorar lo esencial de la estética y arte indigenista. Desde este movimiento los artistas mexicanos expresaron sus inquietudes sociales y culturales a través de la pintura y el muralismo, 
El sacudimiento político-social, en México, había desarrollado el asombroso proceso de las más amplias afirmaciones y reafirmaciones culturales, del seno de la revolución, había surgido un movimiento plástico que, apoyándose en profundas raíces indígenas, iba incorporando al patrimonio universal la trascendencia y la coherencia del arte latinoamericano. Entre sus mayores representantes se encuentran Diego Rivera, David Alfaro Siqueiros, José Clemente Orozco y el maestro José Guadalupe Posada.

Diego Rivera, se caracterizó por sus posiciones políticas trotskistas. El artista se involucró con el arte parisino entre 1907 y 1912. En su momento siguió las ideas renovadoras del arte occidental; $y$, posteriormente se deslindó y se dedicó al movimiento muralista de su país natal. Rivera, produce una pintura muy arraigada con el indigenismo y los cambios históricos de México. Desde su posición política, el capitalismo. Sus murales plantean la contradicción de clases, satirizado las imágenes del capitalismo. Otro artista importante en este movimiento fue David Alfaro Siqueiros, ligado a la actividad política y artística en México. Siqueiro, se interesó por un arte monumental heroico, basado en las tradiciones de América. A través de este arte, el artista expresa la idea de construir un arte monumental, ligado a la actividad política y artística, manifiesta su adhesión a un arte humano, un arte público con el ejemplo directo y vivo de las grandes y extraordinarias culturas prehispánicas de América.
Figura 2 - Lucha por la Independencia, Diego Rivera, entre 1922 y 1923

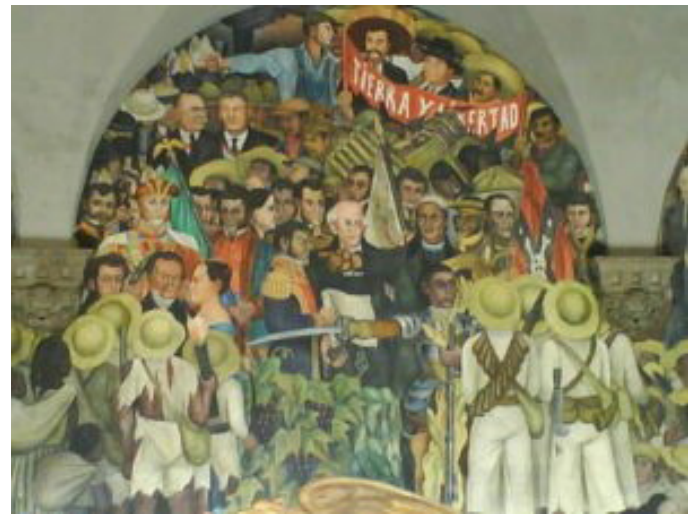

Fuente: <https://www.lifeder.com/muralismo-mexicano/>.

Formado en su propio país, México, José Clemente Orozco mantuvo su actividad artística a través del muralismo. El artista mexicano sostuvo que la verdadera tradición artística viene del arte indígena, arte que dio los cimientos a su arte.

El arte popular mexicano, encontró su lugar dentro de la corriente del muralismo, que renace entre los años 1920 a 1925. Expresa los temas costumbristas como las escenas cotidianas, labores de la mujer, el campesino labrando la tierra, e incluso los artistas se inspiraron en el humor del pueblo, convirtiéndose en temas para la pintura mural, lo que permitió reflejar otras características del mexicano: la humildad pasmosa y la sencillez de un pueblo excluido de los temas en el arte.

En Venezuela, a mediados del siglo XX, algunos pintores de vocación social buscaron su fuente de inspiración en los orígenes más remotos. Estos encontraron un modelo ideal en las culturas precolombinas, las tradiciones pluriculturales y las luchas sociales 
en los diferentes pueblos de América Latina para echar las bases de una plástica nacional, que reivindicara el pasado de nuestras culturas originarias y valorara lo indígena, a través del modelo artístico (realismo social) generaron una nueva lectura ante el arte hegemónico de los años treinta.

Según Noriega, "el realismo social había introducido una nueva iconografía sobre las bases de nuevas fuentes de inspiración. Estas se buscaron en la tradición indígena y en la tradición africana de nuestra cultura" (1989. p. 88). Entre los artistas que respondieron a estos ideales se encuentran: Gilberto Antolínez, Héctor Poleo, Pedro León Castro, Gabriel Bracho, Pedro Centeno Vallenilla, Lorenzo Calzadilla y César Rengifo.

\section{Aportes del arte contemporáneo en Venezuela, caso Mito de Amalivaca}

A partir de uno de los mitos más importantes de la oralidad indígenas de Venezuela, diversos artistas nacionales orientaron sus propuestas estético-artisticas hacia el Mito de Amalivaca. Como recurso interpretativo para generar diversas narrativas plásticas emplearon una perspectiva textual del mito, lo que permitió reinterpretarlo bajo las experiencias pláticas, del relato, tomaron aspectos simbólicos, plásticos y constructivos surgidos de la interacción con el Mito de Amalivaca.

La esencia del Mito Amalivaca, originario de la extinta etnia tamanaco, da cuenta de un gran suceso natural producido por un gran diluvio, que inunda y devasta a los habitantes del Orinoco y es Amalivaca, junto a su hermano vochi que logran salvar a los indígenas tamanacos. Posteriormente la deidad les enseña todo sobre la cultura indígena a los tamanacos, entre las que se encuentran: La artesanía y modos de vidas derivadas del moriche la palma sagrada.

Así, se encuentra el etnólogo Gilberto Antolínez, en Galindez (2003) presentando un linóleo donde representa a Amalivaca decorativo, lleno de elementos simbólicos. Antolínez empleó, en la elaboración del grabado, elementos simbólicos extraídos de los petroglifos venezolanos, específicamente del Estado Bolívar. También utilizó material arqueológico, estudiado a partir de las vasijas mayoide, al igual para las representaciones míticas de los totem naturales de fauna y flora. Asimismo apoyó su estudio en algunas referencias bibliográficas entre las que se cuentan Saggio D'historia Americana, por el Fraile Gilij, Cuadros de la Naturaleza, de Alejandro Von Humboldt, en el Sur Dialectos Indígenas, de Tavera Acosta y otros.

A finales de 1955, el artista plástico, poeta, y dramaturgo César Rengifo realiza un mural de noventa metros cuadrados ubicado en la plaza Diego Ibarra, del Centro Simón Bolívar de Caracas, en el que representa el mito Amalivaca, planificado, diseñado y ejecutado por el artista y un conjunto de colaboradores, que concluyó en un año y seis meses e inaugurado cuando Caracas llegaba al millón de habitantes.

Rodríguez citado en Galíndez (2003) señala sobre la obra del pintor y dramaturgo César Rengifo, que "El mito es posterior al neolítico por cuanto en él se refiere a productos humanos históricos, que tienen su origen en este período, tales como la canoa, la vela y el uso del viento para la navega- 
ción, el cultivo de frutas y el uso de semillas" (RODRÍGUEZ, 1987 apud GALÍNDEZ, 2003, p. 21).

Desde esta óptica, el artista hace referencia al tránsito de las comunidades nómadas a sociedades sedentarias, a la ordenación de la tierra, la creación de la navegación, al nacimiento del cultivo y de la artesanía. Aspectos que destacó en su experiencia muralista a través de su obra.

El artista plástico César Rengifo realizó un mural donde la presencia de la figuración es un elemento plástico esencial para la representación del mito de Amalivaca. Su contribución representó para la década de los años cincuenta la labor muralista más ambiciosa del arte Venezolano.

Figura 3 - Mural de Amalivaca, Centro Simón Bolívar, Caracas, Venezuela

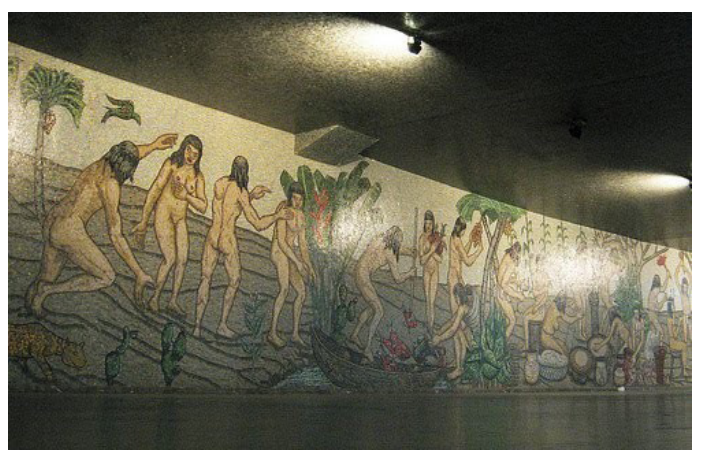

Fuente: acervo del autor.

En las últimas dos décadas de este siglo $X X$, se encuentran numerosos artistas contemporáneos que han tomado como fuente de inspiración los motivos indígenas, mediante un proceso investigativo en el cual los artistas llegan a involucrarse con el entorno y las etnias venezolanas y producir interesantes resultados, tanto plásticos como teóricos. Cabe resaltar por sus diferentes en- foques a Miguel Von Dangel, quien lo muestra desde una perspectiva mítica; Milton Becerra, con un planteamiento ecológico; Adrián Pujol, desde una visión paisajística y Víctor Hugo Irázabal.

Este último, Víctor Hugo Irázabal (1945), a través de su experiencia dentro del Territorio Federal Amazonas, siguió la ruta de Humboldt y desarrolló su propuesta de investigación plástica motivado por la experiencia vivida en la zona de los yanomamis, aquí observa la cultura material de los indígenas, figuras geométrica antropomorfas y zoomorfas, presentes en las piedras milenarias del Amazonas. En esta muestra, se encuentra la obra Amalivaca, pieza emblemática, realizada por el artista en su exposición Amazonia.

Figura 4-Técnica dibujos sobre papel, Amalivaca, 1996

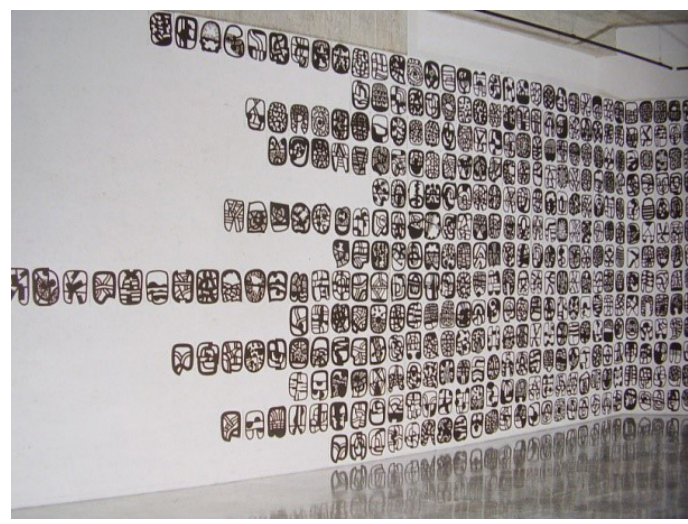

Fuente: acervo del autor.

Esta obra, de considerables dimensiones, despliega novecientos signos representados en unos formatos de papel hecho a mano de $22 \times 28 \mathrm{cms}$, sobre una superficie de $3 \times 18 \mathrm{mts}$. Cada dibujo opera como unidades de un gran conjunto sobre un espacio 
fragmentado y se forma por la integración de sus partes. Cada uno de los 900 signos-dibujos atado a los demás, cada uno naciendo del anterior y dando a luz al próximo, como un discurso infinito, de una coherencia circular e invariable.

Cabe destacar que en esta obra se observa un alto grado de abstracción y síntesis sígnica. Formas cerradas, no referenciales que se expresan en sí mismas abiertas a cualquier interpretación de los observadores. $\mathrm{Al}$ mismo tiempo, ella nace de la experiencia y la vivencia del artista, alimentada por el deseo de observación de las antiguas rocas, de los tiempos míticos expresando lo más espiritual de este entorno natural.

Con respecto a este último Palomero, en Irázabal (1996), apunta que "el primitivismo de Irázabal manifiesta tan solo el anhelo del hombre por recobrar la armonía perdida con un entorno esencial" (1996, p. 129). Otros creadores reconcilian el espacio ancestral y reviven una multitud de íconos olvidados en sus propuestas plásticas, tales como José Bazanta, Giovanny Cardozo, Luís Lizardi, Jesús Matheus y Octavio Ruso.

José Bazanta en su conquista por conservar sus raíces que vive y siente y lo transmite a través de sus obras en un lenguaje plástico ligado al paisaje indígena. Aprecia el mundo donde habita, como hijo adoptivo de las tierras del Caroní. El macizo Guayanés es su inspiración, un mundo misterioso que expresa con la fuerza y sencillez de su alma, donde se contagia y remueven los recuerdos de la niñez, reconociendo la pureza del hombre. Su permanencia en este mundo, su búsqueda dentro de sí mismo, lo conduce al encuentro con sus hermanos yanomami, pemón, herencia materna la cual conserva como un tesoro del Caroní.

Al observar la obra de José Bazanta, se siente el hundimiento de sus pisadas en el charco, las chamizas, entremezclándose con los animales y se convierte en un ritual que compenetra al indio, y su esencia, se siente el espíritu de las montañas y sus ríos formando una melodía que embriaga, donde reposa el pensamiento para escuchar el mensaje que nos trasmite la naturaleza.

Este artista deslinda una concepción del paisaje desde los lumínicos enramajes arabescos de sus paisajes, redefiniéndolo radicalmente, se plantea como un ente en disolución, emplea las telas intervenidas, desgarradas, desflecadas, arrugadas, bajo una paleta oscura que semeja el arrasamiento del fuego.

En el paisaje inicial, lo domínate es la línea gestual y expresiva unida a paletas incendiarias de calor; ahora es el paisaje en su concepción final de destrucción. La selva tupida de ramajes policromados se interpreta quemada, incendiada hasta la total desaparición de su lúcida materia cromática y es ahora una oscura amalgama de sombras. De ella sólo quedará el resto "chamuscado", el testimonio arqueológico de esa naturaleza, el estado final de un proceso.

El artista construye y sostiene su discurso plástico sobre un paisaje vivido donde la naturaleza es su principal motivo: practica un gestualismo e interviene las materias pegando, doblando linos enteros, fragmentados o desgarrados sobre el soporte. Se trata de una obra que atrapa los elementos estéticos de la naturaleza color forma textura y el testimonio que esta soporta por los embates 
del hombre. Mientras que Giovanny Escala Cardoso (1955) configura a través de estos años un lenguaje pictórico absolutamente personal se acerca a los volúmenes y se encuentra entre la voluptuosidad del color hecho forma, signos y geometría de estructura primaria y amorfas, enfatiza el clima casi sacro de la imagen inscrita como trazos rasgados de tiempos en sus lienzos, logrando conferirle mayor homogeneidad, coherencia personal al discurso que infunde cierta agresividad al contenido del pasado sugerido.

Figura 5 - Danza Breve I Serie Danzas de Shaman, $100 \times 80 \mathrm{cms}, 2009$

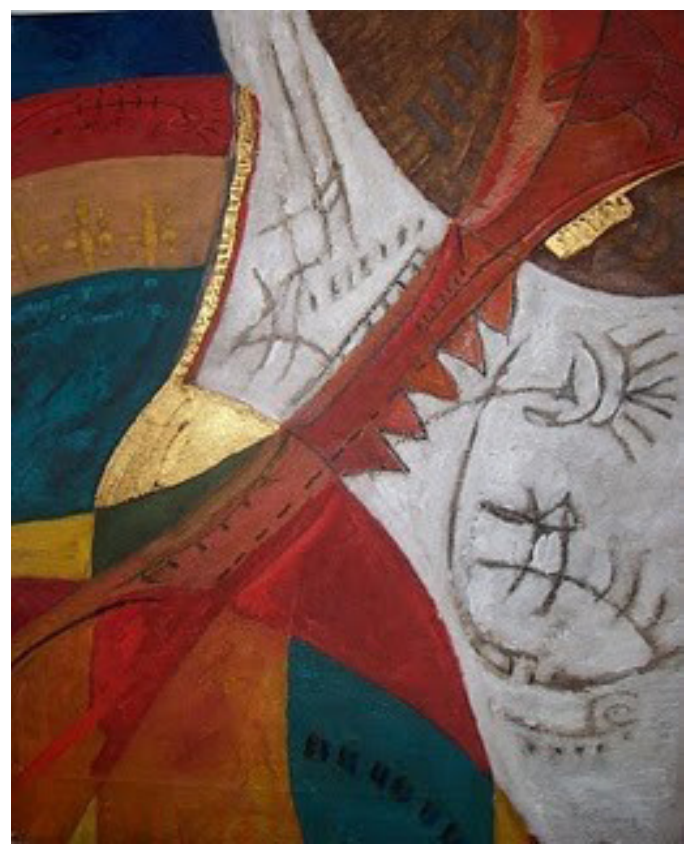

Fuente: acervo del autor.

Penetrar hacia contenidos vinculados con lo hermoso en su acepción visceral o emotiva como descarga expresionista que se hace materia en obras que aluden a un particular contenido espiritual y amor a la natu- raleza. Las connotaciones inmemoriales en la relación enigmática, el culto a lo primitivo y los poderosos sentimientos de religiosidad muestran símbolos que median entre el ser y el hombre tratando de restituir afanosamente esa unidad celestial, eterna, perdida por la humanidad y la naturaleza cósmica.

El artista asimila los códigos que emergen de nuestros indígenas como un gesto de afianzamiento en el rescate de lo inmemorable. La obra manifiesta una reflexión sobre la pintura y los signos ancestrales. Construcción que elabora a través de un acercamiento a las piedra sagradas, elementos gráficos que propician un resultado plástico sólido respaldado por una texturización inobjetable. Escala Cardozo ha volcado su pasión creadora a preservar la memoria de los ancestros, a veces a nivel de culto que, ante la convulsión de hoy, nos trasmite tranquilad.

Otro artista venezolano que expresa sus contenidos artísticos desde los motivos indígenas es Milton becerra, en el año 2009 realiza la exposición Ale'ya (Libro del principio de las verdades escritas), El artista expresa en esta muestra su interpretación de los mitos y símbolos propios de la etnia Wayúu. Es a través de nombres como: Maleiwa, Juya Kai, Pulowi, Tinmijay, Shanceta, Acaracuy, Keerraria, Yuruja, Aalassu que designan la cosmología, flora y fauna, mitos y símbolos, y así hacen ver sus vinculaciones espirituales, comenta Milton Becerra. 
Figura 6 - Maleiwa, $100 \times 100 \mathrm{cms}, 2009$

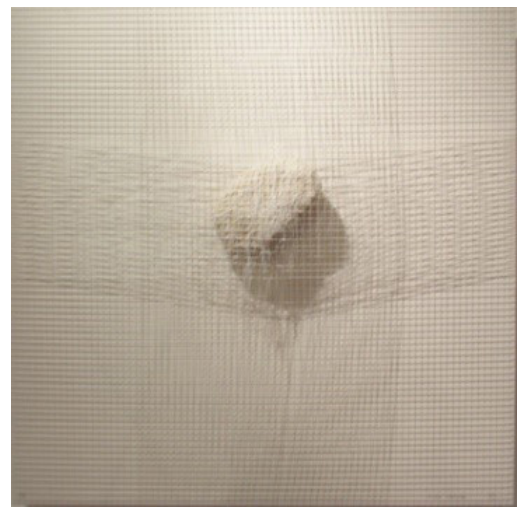

Fuente: acervo del autor.

La muestra está conformada por una instalación con un total de 10 obras de mediano y gran formato, Ensamblajes de metal, piedras y fibra vegetal, que describen gráciles dibujos en el aire sugiriendo vertiginosos movimientos orbitales, toman el espacio para crear una atmósfera llena de transparencias a través del tejido, donde se refleja una vez más la tendencia étnica del artista, así como su interés por la naturaleza, la geometría y la cultura prehispánica.

Mediante el uso de soportes sintéticos que envuelven materiales orgánicos como hojas, troncos, plumas, y piedras, Milton Becerra evoluciona en su mismo lenguaje hacia nuevas formas de amarres en estructuras que proyectan formas geométricas. $\mathrm{Su}$ propuesta artística Ale'ya es poseedoras de una singular fuerza simbólica, las obras en esta muestra nos remiten a un mundo primigenio.
Figura 7 - Komi tinta sobre papel

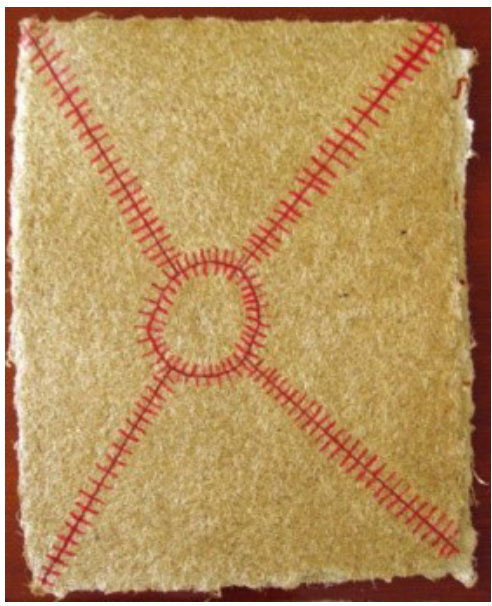

Fuente: acervo del autor.

En 2010, Sheroanawë Hakihiiwë, valiéndose de su memoria, reconstruyó y recreó el universo de la pintura corporal yanomami. El artista se expresó en una muestra plástica denominada Õni Thë Pë Komi "Todos los dibujos están terminados...". Sheroanawë Hakihiiwë nació en Sheroana y vive actualmente en la comunidad de Platanal (Mahekoto-teri) en el Alto Orinoco. Durante la década de los noventa, tuvo la oportunidad de conocer y aprender de la artista mexicana Laura Anderson Barbata la elaboración de papeles artesanales hechos con fibras nativas como el Shiki o la Abaca y el grabado de madera. De esta experiencia, de muchos años de arduo trabajo, nació en 1992 el proyecto inicial Yanomami Owë Mamotima (que en castellano: El arte yanomami de reproducir papel). Junto con Anderson Barbata y la comunidad de Platanal, Sheroanawë emprende la labor de rescatar la memoria oral de su pueblo, a través de la publicación de libros editados por ellos mis- 
mos, como Shapono, hecho con hojas de papel abaca y pigmentos extraídos de semillas, flores y maderas.

La colección de 33 dibujos representa parte del legado ancestral del pueblo de Sheroanawë; es un ejercicio desde la memoria, esa que se va borrando con la llegada del Nape (extranjero) y sus costumbres. Onni Thë Pë Komi - (todos los dibujos están terminados) - ya no sobre los cuerpos de los guerreros y las mujeres del Alto Orinoco, sino realizados esta vez sobre papel de fibra artesanal. Estas acuarelas constituyen, sin duda, una oportunidad única e invalorable para acercarnos al sentir de este pueblo a través de su arte

\section{Abstract}

For the understanding of this article it is important to expose some historical reflections on aesthetics, beginning with a brief synthesis of Western aesthetic philosophy. After considering the Eurocentric criteria of aesthetic domination, the ideas on Latin American thought and the aesthetics of indigenous peoples in Venezuela are addressed. Finally, important Latin American artistic valuations, as well as interesting contributions of contemporary art in Venezuela, Mito de Amalivaca case. Indigenous aesthetics as an object of sensitive knowledge, within social practices (mythical-symbolic), stimulates the interest for the re-existence and visivilization of our native peoples.

Keywords: Art. Assessment. Indigenous aesthetics.
Resumo

Para a compreensão deste estudo, é importante expor algumas reflexões históricas sobre estética, começando com uma breve síntese da filosofia estética ocidental. Depois de considerar os critérios eurocêntricos de dominação estética, as ideias sobre o pensamento latino-americano e a estética dos povos indígenas na Venezuela são abordadas. Finalmente, são discutidos importantes valorações artísticas latino-americanas, bem como interessantes contribuições da arte contemporânea na Venezuela, caso Mito de Amalivaca. A estética indígena como objeto de conhecimento sensível, dentro de práticas sociais (mítico-simbólicas), estimula o interesse por reexistência e visibilização dos povos nativos.

Palavras-chave: Arte. Estética indígena. Valorização.

\section{Nota}

1 Entre las piezas importantes de la cerámica prehispánica se encuentran la figura femenina, cuyo nombre de "Venus" y que se aplicó por asociación a las llamadas irónicamente "Venus del Paleolítico", descubierta por el Dr. Antonio Requena hacia 1.930 - en excavaciones del lago de Valencia, La estatuilla es de arcilla modelada cuyo nombre indígena es Tacarigua: una mujer importante de cráneo rectangular de cuerpo pequeño. 


\section{Referencias}

CRUXENT, José María; ARROYO, Miguel; DE ATENCIO, Sagrario Pérez Soto. Arte Precolombino de Venezuela. Caracas: Fundación Eugenio Mendoza, 1973.

BOULTON, Alfredo. El arte de la cerámica aborigen de Venezuela. Caracas: Imprenta S. P. A. Antonio, 1978.

CALZADILLA, Aangela. Ideología y práctica Artística en el Pintor Gabriel Bracho. Caracas: Fondo Editorial de la Universidad Pedagógica Experimental Libertador, 2004.

CALZADILLA, Angela. La Carga Estético-Artístico del Venezolano Originario. Revista Ciencia y sociedad ULAC, Caracas, a. 1, n. 1, p. 38-52, 2010.

COLOMBRES, Aldolfo. Teoría Transcultural del Arte. Hacia un pensamiento visual independiente. Buenos Aires: Ediciones del Sol, 2005.

DELGADO, Lelia. Huella de lo sagrado, estética y Grafismo Originarios. Grabación en Charla hecha por Luis Galindez, sobre la estética y grafismo originarios, Galería de Arte Nacional. Caracas, marzo 2010.

DELGADO, Lelia. Seis ensayos sobre Estética Prehispánica en Venezuela. Caracas: Biblioteca Nacional de la Historia, 1989.

GALINDEZ, Luis. Mito de Amalivaca, propuesta de creación plástica, 2003. Trabajo de Maestría (Artes Plásticas) - Universidad Pedagógica Experimental Libertador, Instituto Pedagógico de Caracas, 2003.

IRÁZABAL, Victor Hugo. Amazonia. Apuntes de la Inmensidad. Caracas: Colección Artes Visuales, 1996.

MARTÍNEZ MIGUELEZ, Miguel. Ciencia y Arte en la Metodología Cualitativa. México: Trillas, 2006.
MENDIOLA GALVÁN, Francisco. Arte Rupestre: Epistemología, Estética y Geometría, sus Interrelaciones con la Simetría de la Cultura, Ensayo de explicación sobre algunas ideas centrales de Adolfo Best Maugard y Beatriz Braniff. 2002. Disponible: <http//RupestreWeb. tripod.com/mendiola2.html>. Acceso en: 20 ago. 2018.

NORIEGA, Simón. El realismo en la pintura venezolana. Mérida: Universidad de los Andes, 1989.

VELÁSQUEZ, Ronny. Estética aborigen. Caracas: Fundarte, 2003. 